\title{
Self-evaluation in a geometrical optics laboratory with a large number of students
}

M. Melgosa, R. Huertas, A. Yebra, M. Pérez, M. Rivas, et al.

M. Melgosa, R. Huertas, A. Yebra, M. M. Pérez, M. J. Rivas, R. GarcíaMonlleó, M. A. Pérez, E. Valero, E. Hita, J. Arasa, N. Tomás, M. Arjona, M. L. Calvo, "Self-evaluation in a geometrical optics laboratory with a large number of students," Proc. SPIE 9663, Eighth International Topical Meeting on Education and Training in Optics and Photonics, 96632M (6 October 2003); doi: $10.1117 / 12.2208385$

Event: Eighth International Topical Meeting on Education and Training in Optics and Photonics, 2003, Tucson, Arizona, United States 


\title{
Self-evaluation in a Geometrical Optics laboratory with a large number of students
}

\author{
M. Melgosa (1), R. Huertas (1), A. Yebra (1), M.M. Pérez (1), M. J. Rivas (1), R. García-Monlleó (1), M.A. \\ Pérez (1), E. Valero (1), E. Hita (1), J. Arasa (2), N. Tomás (2), M. Arjona (2), and M.L. Calvo (3) \\ (1) Departamento de Óptica. Universidad de Granada. 18071 - Granada, Spain. Tel: 34 958246364. Fax: 34 958248533. Email: \\ mmelgosa@ugr.es (2) Centro de Desarrollo de Sensores y Sistemas CD6. Universidad Politécnica de Catalunya. 08222 - Terrassa (Barcelona), \\ Spain. Tel: 34 937398355. Fax: 34 937398923. Email: arasa@oo.upc.es. (3) Departamento de Óptica. Facultad de Físicas. Universidad \\ Complutense de Madrid. 28040 - Madrid, Spain. Tel: 34 913944684. Fax: 34 913944683.Email: mlcalvo@fis.ucm.es.
}

\begin{abstract}
After each laboratory session, students must answer individually three random multiple choice questions. The corresponding software has been developed by us. This self-evaluation test motivates students before and during sessions performance, and provides objective information to the teacher. The estimated students' mean satisfaction with this system is 8.1/10.

(C)2003 Optical Society of America

OCIS codes: (000.2060) Education; (080.0080) Geometrical optics
\end{abstract}

Specific software for self-evaluation in the geometrical optics laboratory (first course for the optics and optometry diploma) has been developed. Later it has been used by 141 undergraduate students during a total of 8 sessions. After each session, and using a personal password, students must answer individually a three four-option questionnaire, randomly selected from a database with 124 questions. There was a response time limit of $45 \mathrm{~s}$ per question, and the answers were processed in the computer. The goal of this self-evaluation test is to motivate students' learning before and during laboratory sessions, and also to provide objective information to the teacher, who is usually responsible for a laboratory with 24 students per session. Our proposed self-evaluation software could be easily implemented in other undergraduate optics laboratories.

Figure 1 shows the mean percentage (and standard deviation) of correct answers by our students, corresponding to each one of the 8 laboratory sessions. An overall average of $78.2 \%$ correct answers was found, with similar results for all sessions: 1. Visualization of ray trajectories through simple Optical Systems, and measurement of the refractive index of a plane-parallel plate; 2 . Verification of paraxial equations for a converging lens; 3 . Measurement of focal lengths of converging and diverging lenses; 4. Determination of the cardinal points of an optical system formed by two lenses; 5. Dispersive prisms: measurement of refractive indices at different wavelengths; 6 . Measurement of radius of curvature for concave and convex mirrors; 7. Compound microscope: measurement of magnification of the objectives, and refractive indices of plane-parallel plates; 8. Effect of aperture and field stops, and visualization of geometrical and chromatic aberrations.

Figure 2 shows the mean results and standard deviation of a survey where the next 8 questions were posed to the students: 1 The use of the computer program is: very difficult (0); very easy (10); 2 . The proposed questions are related to the laboratory handbook and to the experimental work that you have done: not at all (0); very closely (10); 3 . The proposed questions are: very difficult $(0)$; very easy $(10)$; 4 . The time available for answering each question is: very short (0); very long (10); 5 . With this system the performance of the laboratory sessions improves: not al all (0); very considerably (10); 6 . This self-evaluation system is: very stressful (0); not stressful at all (10); 7. Do you think this system should be used in other undergraduate laboratories to improve learning?: never(0); always (10); 8. Please mark globally this self-evaluation procedure to improve laboratory teaching in geometrical optics: very bad (0); very good (10). We are particularly encouraged by the high mean score obtained for this last question: 8.1/10.

Eighth International Topical Meeting on Education and Training in Optics and Photonics, edited by Barry L. Shoop, Grover Swartzlander Jr., Proc. of SPIE Vol. 9663, 96632M

(C) 2003 SPIE, OSA, ICO · doi: 10.1117/12.2208385 

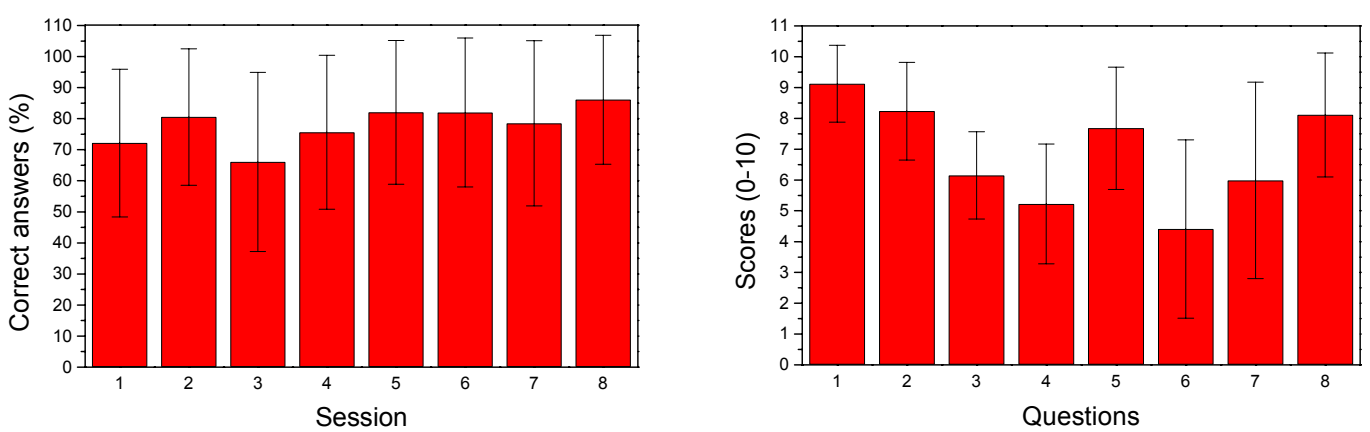

Fig 1. Percentage of correct answers (left), and results of a survey (see text) passed to the students (right).

Proc. of SPIE Vol. $966396632 \mathrm{M}-2$ 